\title{
REFLEXÕES ACERCA DA VIOLÊNCIA DE GÊNERO NO AMBIENTE ESCOLAR
}

\begin{abstract}
Anaquel Gonçalves Albuquerque ${ }^{1}$
RESUMO. O recorte que o texto em tela faz é a apresentação das primeiras etapas de uma pesquisa em andamento na Universidade do grande Rio - UNIGRANRIO intitulada "Um Estudo de Caso sobre a Violência de Gênero em uma Escola Municipal na Baixada Fluminense". O estudo tem como objetivo principal diagnosticar qual a percepção que os estudantes do CIEP 200 - Recanto dos Colibris, localizado na cidade de Nova Iguaçu, no estado do Rio de Janeiro tem sobre a Violência de gênero. O estudo realizado teve como metodologia o levantamento de dados quantitativos realizados com alunos da referida escola. O resultado da aplicação de questionário mostrou que a maior parte dos estudantes acreditam que a criação da Lei Maria da Penha tem um papel importante no combate e prevenção à violência de gênero.
\end{abstract}

Palavras-chave: Educação; Gênero; Violência

\section{REFLECTIONS ON GENDER VIOLENCE IN THE SCHOOL ENVIRONMENT}

ABSTRACT. The clipping that the text on canvas makes is the presentation of the first steps of a research in progress at the University of the Great Rio - UNIGRANRIO entitled "A Case Study on Gender Violence in a Municipal School in the Baixada Fluminense." The main objective of this study is to diagnose the perception that students of CIEP 200 - Recanto dos Colibris, located in the city of Nova Iguaçu, in the state of Rio de Janeiro, have on Gender violence. The study was carried out using quantitative data collected from the students of this school. The result of the questionnaire application showed that most of the students believe that the creation of the Maria da Penha Law plays an important role in combating and preventing gender violence.

Keywords: Education; Genre; Violence

\section{INTRODUÇÃO}

O presente artigo faz parte da primeira etapa de uma pesquisa em andamento na Universidade do grande Rio - UNIGRANRIO que tem como tema de pesquisa

\footnotetext{
${ }^{1}$ Mestranda do Programa de Pós Graduação em Humanidades, Cultura e Artes - UNIGRANRIO. Articuladora pedagógica pela Secretaria Estadual de Educação do Rio de Janeiro - SEEDUC. anaquelalbuquerque@hotmail.com
} 
"Violência de Gênero: Um Estudo de Caso em uma Escola Municipal na Baixada Fluminense". O CIEP 200 - Recanto dos Colibris localizado na cidade de Nova Iguaçu, no estado do Rio de Janeiro foi o lócus escolhido para investigar as percepções que os estudantes têm sobre a violência de gênero.

$\mathrm{Na}$ primeira parte do presente artigo apresentaremos uma discussão sobre os conceitos de gênero e violência de gênero, para isso, nos basearemos nas concepções teóricas de Scott (1995), Foucault (2011, 1999), Bordieu (1999), Louro (1997), Butler (2015), Priori (2007), Saffioti (2001), dentre outros estudiosos do assunto, por suas relevantes contribuições no campo dessa temática. A seguir, faremos uma breve exposição sobre a Lei 11.340, conhecida como Lei Maria da Penha que se constitui como importante assunto para a discussão acerca da violência e da discriminação de gênero no universo social. Finalmente, apresentaremos os resultados parciais da pesquisa que procedeu por meio da utilização de método quantitativo a fim de compreendermos o que os estudantes entendem por violência de gênero.

\section{Os estudos de gênero}

Os estudos de gênero surgiram no campo das ciências sociais a partir da década de 1970, em substituição ao que seriam denominados estudos sobre a mulher, e se constituem como um campo de pesquisa interdisciplinar cujo objetivo é compreender as relações de gênero no mundo social. A emergência desses estudos representou a ruptura com a tendência de se buscar no determinismo biológico a explicação para as desigualdades entre homens e mulheres, promovendo assim, dentre outras coisas, a superação das teorias dos papéis sexuais e da complementaridade dos sexos. Nesse sentido, a análise das desigualdades de gênero consiste na identificação de como se constituem as relações entre homens e mulheres face à distribuição de poder ou, qual a equivalência social entre os gêneros. A concepção de gênero pode ser "concebida como a construção sociocultural do significado de ser homem e ser mulher em uma determinada sociedade" (PRIORI, 2007, p.15).

Sendo assim, conceituar gênero seria um processo tão complexo como determinar um significado único para a palavra violência, visto que vivemos em uma sociedade onde predominam normas modeladoras, definindo categorias sociais em 
homem ou mulher, dependendo tão somente de suas condições ao nascer e reafirmando uma natureza binária que especifica também o sexo em masculino ou feminino. Butler $(2015$, p.44) aborda esta questão complexa ao afirmar que

\begin{abstract}
A matriz cultural por meio da qual a identidade de gênero se torna inteligível exige que certos tipos de "identidade" não possam "existir" - isto é, aqueles em que o gênero não decorre do sexo e aqueles em que as práticas do desejo não decorrem nem do sexo nem do gênero. Ora, do ponto de vista desse campo, certos tipos de "identidade de gênero" parecem ser meras falhas do desenvolvimento ou impossibilidades lógicas, precisamente por não se conformarem às normas da inteligibilidade cultural.
\end{abstract}

Ao longo do tempo as sociedades foram definindo papéis e funções diferenciadas aos sujeitos em conformidade com a identidade de gênero. Como exemplo podemos citar a situação da mulher que, no passado, já foi identificada como propriedade do pai (no período colonial, bem como imperial brasileiro), ou até mesmo do marido, sem qualquer tipo de direitos, sejam eles políticos, econômicos ou sociais. Tal desigualdade deu origem a uma intensa luta do movimento feminista como forma de não aceitação das normas desiguais que eram impostas a homens e mulheres, refletindo em um cenário onde os indivíduos configuram como dominadores ou dominados.

Para Bordieu (1999, p, 23-24) o conceito de gênero está relacionado a uma estrutura de dominação simbólica no qual "o princípio masculino é tomado como medida de todas as coisas sabendo assim, que o homem e a mulher são vistos como duas variantes, superior e inferior”. Desta forma, para o autor, a diferença biológica existente entre os sexos seria utilizada como justificativa para a diferença construída socialmente entre os gêneros.

Segundo Scott (1995), somente no final do século XX a categoria gênero aparece como uma preocupação teórica visto sua ausência em grande parte das teorias sociais, desde o século XVII até o início do século XX. Durante este período se discutiam questões desde a oposição entre masculino/feminino, tendo como ponto de partida o reconhecimento da existência de uma questão feminina, à definição de uma identidade sexual. Não existia nas análises e estudos o conceito de gênero, como forma de identificar as relações sociais existentes entre os indivíduos. 
É necessário, ainda, compreender que os conceitos de gênero e de sexo relacionam-se entre si, mas não significam a mesma coisa. A expressão sexo relacionase com a natureza, e descreve as características biológicas que diferenciam sexualmente, machos e fêmeas de todas as espécies. Já no que concerne ao gênero, este está relacionado à cultura, e designa os papéis e atributos de homens e mulheres nas sociedades. Sendo assim, as diferenças biológicas são constantemente transformadas em desigualdade de gênero (SAFFIOTI 2001).

Na concepção de Scott (1995) gênero é um elemento constitutivo das relações sociais, baseado nas diferenças percebidas entre os sexos, sendo a primeira forma de significar as relações de poder. Desta forma, as desigualdades de gênero se fazem cada vez mais presentes em nossa sociedade hierarquizando as diferenças entre os sexos. A própria autora enfatiza também que as identidades subjetivas funcionam como um importante conceito para o entendimento de gênero, dado que são formadas por processos de diferenciação e de distinção, caracterizando como princípio da masculinidade uma necessária negação dos aspectos femininos, de forma que um só pode ser percebido a partir da diferença que possui para o outro.

Ainda sobre o conceito de gênero, pode-se afirmar que

É uma das referências recorrentes pelas quais o poder político tem sido concebido, legitimado e criticado. Ele não apenas faz referência ao significado da oposição homem/mulher; ele também o estabelece. Para proteger o poder político, a referência deve parecer certa e fixa, fora de toda construção humana, parte da ordem natural ou divina. Desta maneira, a oposição binária e o processo social das relações de gênero tornam-se parte do próprio significado de poder; pôr em questão ou alterar qualquer de seus aspectos ameaça o sistema inteiro. (SCOTT, 1995, p.92)

Desta forma, as relações de gênero estariam diretamente relacionadas a um permanente cenário de reafirmação do poder, sendo marcado geralmente pelo uso da violência.

\section{Gênero e Poder: uma articulação necessária}

O conceito de poder atrelado a discussão das relações de gênero torna-se substancial na compreensão da violência de gênero, desmistificando a oposição entre dominadores, os homens, e dominadas, as mulheres. Para Saffioti (2001) a categoria 
poder torna-se primordial na discussão, contudo não é qualquer aporte teórico que consegue evidenciar as nuances que encobre as relações desiguais entre homens e mulheres, estando imersas pelas relações de poder.

Foucault (2011) também nos traz importantes contribuições para a compreensão das relações de gênero, ao abordar a influência das relações de poder na formação do sujeito, que é formado, definido e reproduzido em conformidade com as exigências dos sistemas jurídicos de poder vigentes na sociedade. Este mecanismo se dá por meio da limitação, proibição, regulamentação, controle e mesmo 'proteção' dos indivíduos relacionados àquela estrutura política, mediante uma ação contingente e retratável de escolha.

Butler (2015, p.19) ressalta que o próprio sistema de poder produz sujeitos com traços de gênero associados a um eixo diferencial de dominação, de forma que

A construção política do sujeito procede vinculada a certos objetivos de legitimação e de exclusão, e essas operações políticas são efetivamente ocultas e naturalizadas por uma análise política que toma as estruturas jurídicas como seu fundamento.

O poder é algo que se exerce em rede de relações, circulando pelos e nos indivíduos, ele deve ser analisado como algo que circula, flui, opera em cadeia, nunca localizado em um ponto, tal como um bem ou a riqueza. Para o autor o poder não é algo que se compartilha e que se detém com exclusividade por alguém ou grupo. Desse modo, os sujeitos são alvos e protagonistas do poder, isto é, o poder transita por eles, não somente se aplica a eles. O poder é o que constitui o indivíduo como tal, seus gestos, seus discursos e seus comportamentos (FOUCAULT, 1999).

Todo individuo possui poder, que transita por ele, o que não deve levar à falsa inferência de que o poder é algo bem distribuído. Desse modo, não se deve deduzir que o poder parte do centro e se prolonga até embaixo, em que medida ele se reproduz ou onde ele se reconduz até os elementos mais atomísticos da sociedade, mas, na realidade, fazer uma análise ascendente do poder, partindo dos mecanismos infinitesimais, que possuem sua própria história, trajetória, técnicas e táticas e, em seguida, observar como esses mecanismos de poder possuem sua solidez e tecnologia própria, e analisar como esses mecanismos foram investidos, colonizados, transformados, deslocados, estendidos por mecanismos cada vez mais gerais e por uma forma de dominação global 
(FOUCAULT, 1999).

Para Foucault (1999) o poder não pode ser tomado por uma substância, uma essência, um conceito ou o que se detém ou cede. O poder é, efetivamente, algo que se exerce, uma série de práticas e estratégias, ligadas a interesses político ocultos, cujo objetivo é dominar. O poder não se concentra em instituições ou centros, mas deve ser vislumbrado como uma rede, que a tudo e todos perpassam, estendendo-se para os saberes e, até mesmo, para o que se entende por verdade. A esses novos arranjos do poder e sua rede de atuação e abrangência, Foucault denomina de microfísica do poder.

Ora, o estudo dessa microfísica supõe que o poder nela exercido não seja concebido como uma propriedade, mas como uma estratégia, que seus efeitos de dominação não sejam atribuídos a uma "apropriação", mas a disposições, a manobras, a táticas, a técnicas, a funcionamentos; que se desvende nele antes uma rede de relações sempre tensas, sempre em atividade, que um privilégio que se pudesse deter; que lhe seja dado como modelo antes a batalha perpétua que o contrato que faz a cessão ou a conquista que se apodera de um domínio. Temos em suma que admitir que esse poder se exerce mais que se possui, que não é o "privilégio" adquirido ou conservado da classe dominante, mas o efeito de conjunto de suas posições estratégicas - efeito manifestado e às vezes reconduzido pela posição dos que são dominados. Esse poder por outro lado, não se aplica pura e simplesmente como uma obrigação ou uma proibição, aos que "não tem"; ele os investe, passa por eles e por meio deles; apoia-se neles, do mesmo modo que eles, em sua luta contra esse poder, apoiam-se por sua vez nos pontos em que ele os alcança (FOUCAULT, 1999, p.30).

Na concepção do autor, o poder acontece como uma relação de forças, coagindo, disciplinando e controlando os indivíduos. Através de seus mecanismos, esta forma de controle se faz presente em toda a sociedade, nos mais diferentes lugares e em todas as pessoas. O poder jamais é propriedade de uma única pessoa, de maneira que a partir do momento em que o grupo desaparece, o poder também se dissolve, havendo a necessidade de união para que este poder se estabeleça (FOUCAULT, 1999).

O poder, embora muitas vezes confundido com a violência, seria correspondente às forças da natureza ou circunstâncias no que se refere aos aspectos físicos e sociais. Já a violência, por sua vez, seria oposta ao poder, distinguindo-se por seu caráter instrumental, e sempre necessitando de justificativa para obter o fim desejado. Assim, “a forma extrema do poder é o Todos contra Um, a forma extrema da violência é o Um 
contra Todos. E esta última nunca é possível sem instrumentos." (ARENDT, 1994, p.35). Ainda de acordo com a autora, o poder que é inerente a toda comunidade política precisa de legitimidade, diferentemente da violência, que requer justificativa.

\section{Construindo papéis de gênero no ambiente escolar}

Como afirma Louro (1997), a escola é um local onde mais se produz as diferenças sejam elas Sociais, Físicas, Étnicas e as de Gênero. Percebe-se que a partir do processo de socialização tais ideias e concepções são passadas e reproduzidas como sendo algo natural.

A escola delimita espaços. Servindo-se de símbolos e códigos, ela afirma o que cada um pode (ou não pode) fazer, ela separa e institui. Informa o "lugar" dos pequenos e dos grandes, dos meninos e das meninas. Através dos seus quadros, crucifixos, santas ou esculturas, aponta aqueles/as que deverão ser modelos e permite, também, que os sujeitos se reconheçam (ou não) nesses modelos. Currículos, normas, procedimentos de ensino, teorias, linguagem, materiais didáticos, processo de avaliação, diferenças de gênero, sexualidade, etnia, classe - são constituídos por distinções e, ao mesmo tempo, seus produtores. Todas essas dimensões precisam, pois, ser colocadas em questão. É indispensável questionar não apenas o que ensinamos, mas o modo como ensinamos e que sentidos nossos/os alunos/as dão ao que aprendem. Atrevidamente é preciso, também, problematizar as teorias que orientam nosso trabalho. Temos de estar atentas/os, sobretudo, para nossa linguagem, procurando perceber o sexismo, o racismo e o etnocentrismo que ela frequentemente carrega e institui (LOURO, 1977, p.58 e 64).

O universo escolar vem tomando um espaço maior, reforçando a segregação entre os sexos e gênero. Podemos dar o exemplo da escola infantil onde existe uma separação das brincadeiras para menino e para meninas, evitando que estes tenham um contato, como também nas pinturas nas paredes da escola, meninos jogando bolas e com carrinhos nas mãos e por outro lado, as meninas com bonecas nos braços e cuidando de plantinhas.

O que acontece nesse espaço é um reforço da construção social, determinando como cada sexo deve se comportar nos diversos espaços. As instituições como escola, 
família e religião estão sempre reforçando os comportamentos de masculinidade e feminilidade, dentro do processo de socialização. A feminilidade e a masculinidade são construções culturais aprendidas durante o processo de socialização. Portanto, ao tratarmos de gênero, estamos nos referindo a socialização dos papéis que levam homens e mulheres a se comportarem diferentemente. Nesse sentido, o comportamento é socialmente construído, e as diferenças entre homens e mulheres são criadas e exacerbadas no processo de aprendizagem, carregados de estereótipos, os quais contribuem para perpetuar a desigualdade de gênero (LOURO 1997).

Silva (2010) esclarece que hoje a política educacional está vinculada a um sistema neoliberal que tem como objetivo os valores econômicos intensamente associados à masculinidade: competitividade, desempenho, racionalidade tecnológica, eficácia, produtividade. Tais objetivos associados às características masculinas levam à discriminação da mulher. Estes conceitos demonstram que é necessário mudar as estruturas educacionais e se voltar à discussão de gênero, dentro das salas de aula, preparando os alunos para atuarem na sociedade de maneira igualitária.

Casagrande (2008) enfatiza que discutir as relações de gênero no ambiente escolar é de fundamental importância quando se pensa em construir uma educação democrática que possibilite a todos os seus agentes, igualdade de condições e de oportunidades. Há, portanto, que sumariamente, considerar as crianças e adolescentes como atores sociais.

Nunes e Silva (2006) acreditam que somente uma educação emancipatória, é capaz de contribuir para a superação das condições de heteronomia, de propor reflexões sobre os contextos de uma sexualidade reprimida proveniente do período medieval - os mitos da superioridade e racionalidade masculina sob a inferioridade e afetividade, exclusivamente feminina, no sentido de promover uma formação que auxilie os educandos a compreenderem a constituição das concepções de gênero e suas vinculações às estruturas sociais.

É necessário reconhecer que as aprendizagens - no tocante às questões de gênero - estão incorporadas em práticas cotidianas formais e informais que nem questionamos mais. Elas atravessam os conteúdos das disciplinas que compõem o currículo oficial ou estão imbricadas na literatura que selecionamos, nas revistas que colocamos à disposição das estudantes para pesquisa e colagem, nos filmes que passamos, no material escolar que indicamos para consumo, no vestuário que permitimos e naquele que é proibido, nas 
normas disciplinares que organizam o espaço e o tempo escolares, nas piadas que fazemos ou que ouvimos sem nos manifestar, nas dinâmicas em sala de aula e em outros espaços escolares que não vemos (LOURO, 1997).

Louro (1997) ainda esclarece que a construção dos gêneros e das sexualidades dá-se através de inúmeras aprendizagens e práticas, insinua-se nas mais distintas situações, é empreendida de modo explícito ou dissimulado por um conjunto inesgotável de instâncias sociais e culturais. É um processo minucioso, sutil, sempre inacabado. Família, escola, igreja, instituições legais e médicas mantêm-se, por certo, como instâncias importantes nesse processo constitutivo.

Certas práticas podem - intencionalmente ou não - fortalecer a violência no âmbito das relações de gênero. Isso ocorre principalmente quando se considera mecanicamente certas características consideradas como femininas às mulheres e, em contrapartida, as masculinas aos homens. Essa associação, em que se considera - por exemplo - determinados sentimentos como tidos do feminino, pode contribuir para uma violência na medida em que exclui a possibilidade de homens terem tais sentimentos, fazendo com que eles se sintam menos homens. Assim, ao se reificar determinadas características como exclusivas de um gênero específico, os discursos podem se configurar como uma faceta da violência (GOMES, 2008).

Casagrande (2008) ressalta que ao se ensinar formas de comportamentos distintos e cobrar das meninas e meninos atitudes correspondentes é natural que haja uma separação entre eles no ambiente escolar, sendo importante que os professores e professoras observem isso e busquem a interação entre todos os alunos e alunas, independentemente do gênero, para que as crianças e adolescentes aprendam a respeitar as diferenças e diminuir as desigualdades entre os gêneros.

Se nos dispusermos a potencializar a escola como espaço privilegiado de construção da igualdade, nossos questionamentos e reflexões serão acompanhados de ações que expressem os desejos por uma sociedade, na qual homens e mulheres possam expressar os seus corpos e expressar-se com os seus corpos; possam usar a imaginação e a criatividade, exercitando-se nas múltiplas e diferentes relações e experiências que poderão ter, sem mais estarem circunscritos em um campo de gênero masculino ou feminino. Nesse sentido, os educadores "devem estar conscientes e entender o poder e 
influência de seu comportamento e atitudes, assim como do que ensinam e de como ensinam" (WHITELAW, 2003, p. 38).

O questionamento e problematização das ordens de gênero instauradas podem “contribuir para perturbar certezas, para ensinar a crítica e a autocrítica, para desalojar as hierarquias" (LOURO, 1997, p. 124).

Um dos pontos fundamentais na educação das crianças é problematizar e desconstruir o sexismo, a heteronormatividade e outros tipos de preconceito, pois eles começam dentro de casa e podem ser reforçados, muitas vezes, dentro da própria escola, que deveria ser um lugar de acolhimento, além de sua função de ampliar os conhecimentos dos alunos e alunas e também dos professores (LOURO 1997).

Assim como em qualquer outra prática docente, há de se enfatizar que ao propor reflexões sobre as questões de gênero no ambiente escolar, é essencial possuir conhecimentos sobre o meio em que o aluno vive - seu lugar afetivo. Além do aspecto psicopedagógico e do ambiente escolar, é preciso respeitar o universo que o aluno/a aluna traz para a sala de aula - universo este que foi - nos anos que antecederam sua entrada na escola - e está sendo constantemente sedimentado. É preciso respeitar a realidade sociocultural do educando e os seus ritmos de desenvolvimento.

\section{O Campo prático da pesquisa}

O CIEP (Centro Integrado de Educação Pública) escolhido para nossa pesquisa localizase na cidade de Nova Iguaçu, no estado do Rio de Janeiro. Atuam como sujeitos da pesquisa 15 alunos do ensino médio da unidade escolar, que participarão de encontros semanais. Acrescenta-se que estes alunos foram selecionados pela pesquisadora mediante a característica de interação e liderança que eles possuem frente aos demais alunos, na perspectiva de que as reflexões realizadas ao longo desta pesquisa possam ser socializadas futuramente junto aos demais alunos da instituição escolar.

\section{Procedimento de coleta de dados}

A pesquisa apresentou uma abordagem quantitativa de caráter descritivo/exploratório. $\mathrm{O}$ questionário foi aplicado em sala de aula, buscando realizar um diagnóstico do que os 
estudantes entendem no que se diz respeito à violência contra à mulher, o questionário, foi aplicado a alunos do $1^{\circ}$ ano no período da manhã. As respostas são realizadas marcando-se um (S) para sim e um (N) para não. O questionário foi desenvolvido após ampla revisão bibliográfica sobre o tema e consulta à literatura específica.

\section{Análise e discussão dos resultados}

Questão 01: Você conhece a lei Maria da Penha? ( ) sim ( ) não

Gráfico 1: Análise da pergunta 1

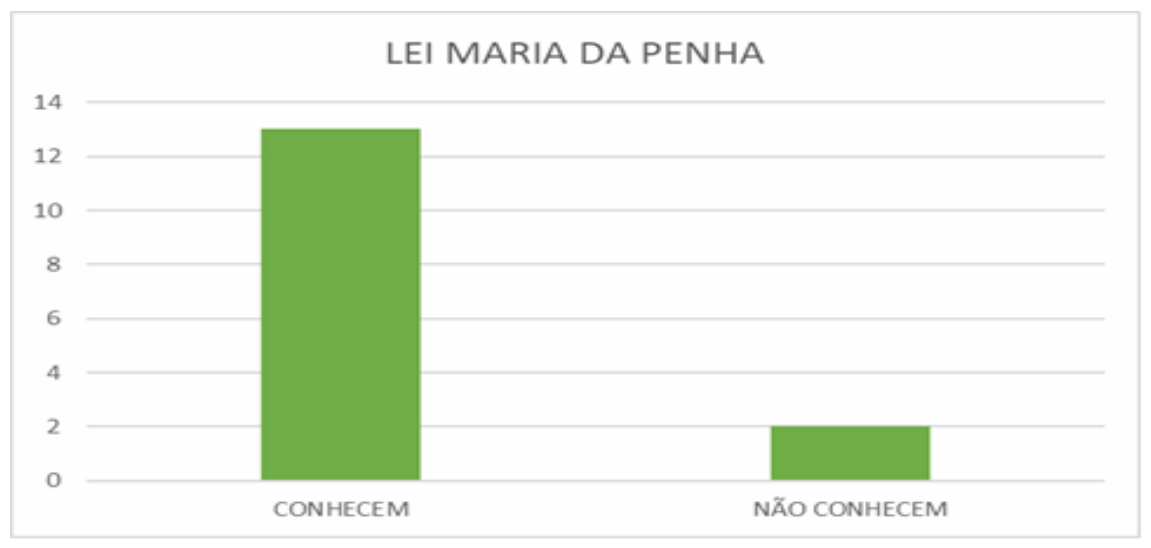

Com as respostas a questão 1 do questionário apresentadas a seguir, foi traçado o gráfico 1, onde pode-se observar que a $73 \%$ dos alunos firmam conhecer a Lei Maria da Penha, enquanto 27\% afirmam não conhecê-la.

Questão 02: Você sabe o que é um relacionamento abusivo? ( ) sim ( ) não

Gráfico 2: Análise da pergunta 2

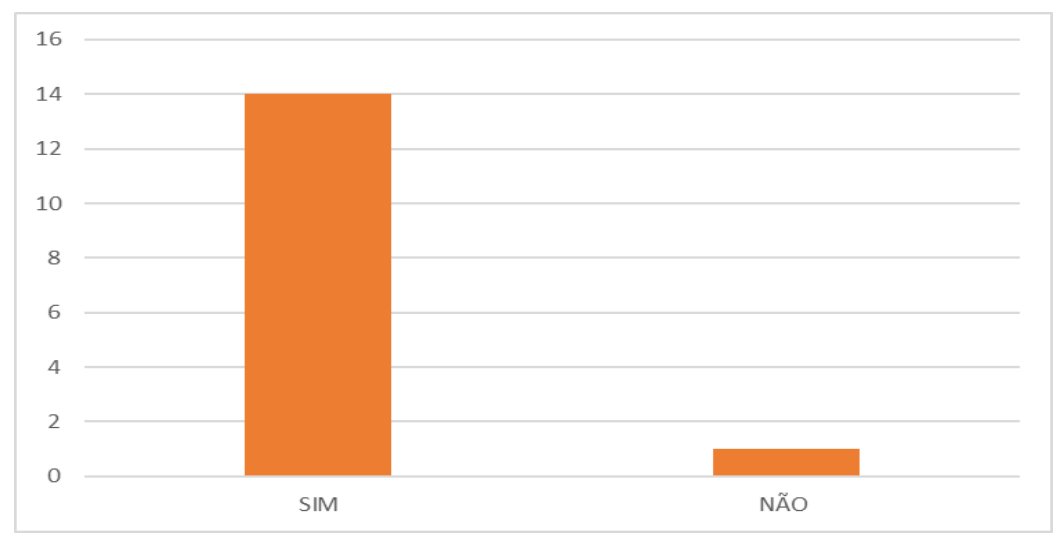

RPI Revista de Pesquisa Interdisciplinar, Cajazeiras, v. 3, n. 1, 49-62, jan/jul. de 2018. 
Com as respostas a questão 2 do questionário, foi traçado o gráfico 2. Este gráfico demonstra que $93 \%$ dos entrevistados afirma saber o que é um relacionamento abusivo e 7\% afirmam não saber.

Questão 03: Você vivenciou ou conhece alguém que tenha vivido um relacionamento abusivo?

Gráfico 3: Análise da pergunta 3

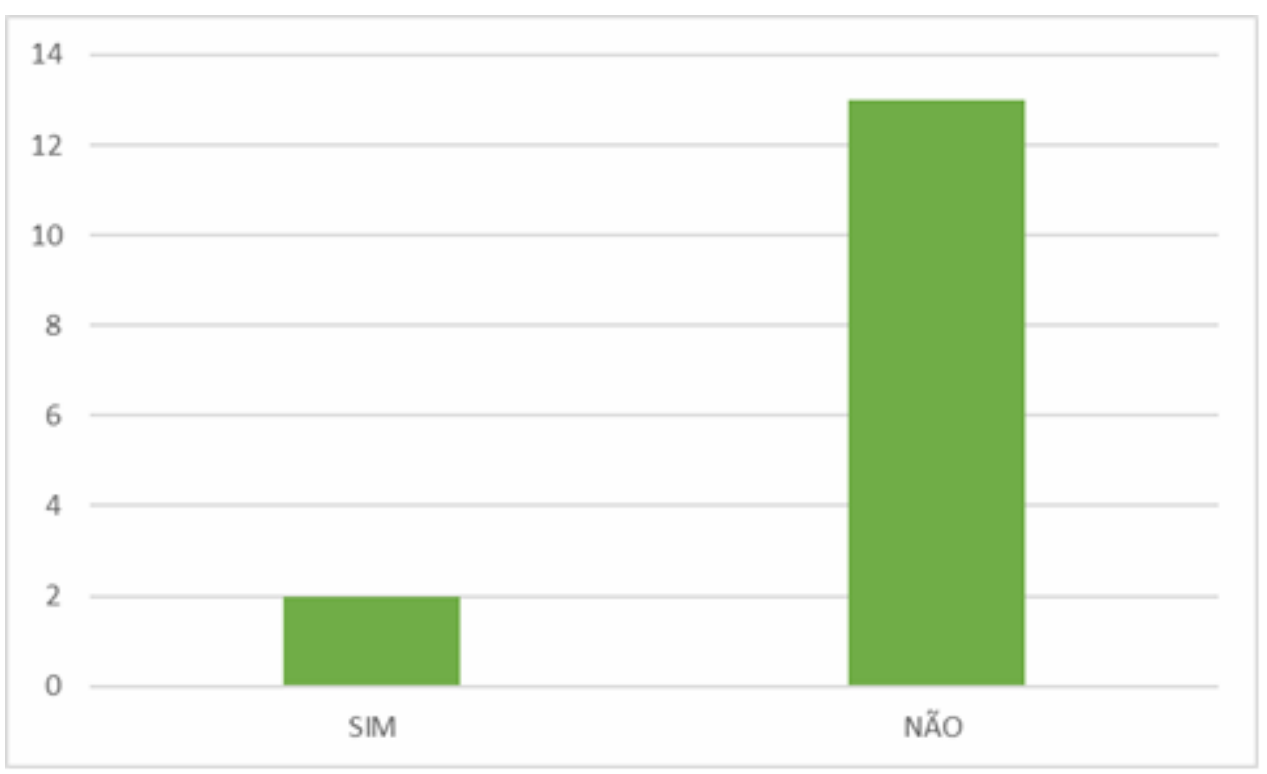

Mesmo que a maior parte dos estudantes consultados saiba do que se trata a Lei Maria da Penha, e que afirmem em sua maioria saber o que é violência de gênero, o gráfico acima expõe o fato de que, nem todos os aspectos da lei e dos tipos de violência são conhecidos.

\section{Desenvolvimento de Intervenções no Ambiente Escolar}

A segunda e última parte do projeto que terá uma abordagem qualitativa, ainda a ser realizada, diz respeito ao desenvolvimento da temática da violência de gênero por meio de rodas de conversa com o objetivo de conscientizar alunos e professores da importância sobre a violência contra a mulher. Durante o desenvolvimento do trabalho os alunos vão ter acesso a vídeos, reportagens, recortes de jornais e revistas relacionados à temática. 


\section{Considerações Finais}

Concluímos que a necessidade de se abordar a temática da violência de gênero na sala de aula é importante principalmente por se tratar de um tema relevante, já que o Brasil é um país que mantém altos os índices de violência de gênero. Nesse sentido, a educação é um fator fundamental para a prevenção e erradicação da violência, por isso, acreditamos que a escola tem papel fundamental na desconstrução da violência contra a mulher.

A proposta de se trabalhar a violência de gênero no ensino médio, vem a somar na questão da valorização do ser humano, auxiliando para que os alunos percebam a importância do outro. No decorrer da primeira fase da pesquisa constatamos a importância do debate acerca da temática, uma vez que a violência se faz presente na vida de muitos de nossos adolescentes e nós, como educadores, não podemos nos omitir, pois a escola é o local onde estes adolescentes vêm buscar conhecimento.

Devemos, portanto, como educadores, abordar o tema incansavelmente para que nossos alunos tenham consciência de que a violência é extremamente nociva, tanto para a família como para a sociedade, e para que eles sejam capazes de reconhecer os mais variados tipos de violência. Acreditamos que assim será possível demonstrar que podemos construir uma um olhar sensível e solidário em relação esse tipo de violência.

\section{REFERÊNCIAS BIBLIOGRÁFICAS:}

ALVES, Leonardo B.M. O reconhecimento legal do conceito moderno de família- o art.5 ${ }^{\circ}$, II e parágrafo único, da lei $\mathbf{n}^{0}$ 11.340/2006, Lei Maria da Penha. Minas Gerais: Revista Jurídica do Ministério Público de Minas Gerais, 2007.

ARENDT, H. Sobre a Violência. Rio de Janeiro. Relume-Dumará,1994.

BOURDIEU, Pierre. A Dominação Masculina. Rio de Janeiro: Bertrand Brasil,1999.

BUTLER, Judith. Problemas de Gênero: Feminismo e subversão da identidade. Rio de Janeiro, Civilização Brasileira, 2015.

CASAGRANDE, L. S.; Educando as novas gerações: representações de gênero nos livros didáticos de Matemática. 2005. Dissertação (mestrado em Tecnologia) - Programa de Pós Graduação Tecnológica, Centro Federal de Educação Tecnológica do Paraná, Curitiba. 
FOUCAULT, Michel. Microfísica do poder. 23. ed. São Paulo: Graal,1999.

História da sexualidade. Volume 1.21 a reimpressão. Rio de Janeiro:

Graal, 2011.

GOMES, Romeu. A dimensão simbólica da violência de gênero. Revista Athenea Digital: revista de pensamiento e investigación social. n. 14, 2008 , págs. 237-243

LOURO, Guacira Lopes. Gênero, sexualidade e educação: uma perspectiva pósestruturalista. Petrópolis, RJ: Vozes, 1997.

NUNES, C. A. Desvendando a Sexualidade. Campinas, SP: Papirus, 2002.

NUNES, C. A. ; SILVA, E. A Educação Sexual da Criança: Subsídios teóricos e propostas práticas para uma abordagem da sexualidade para além da transversalidade. Campinas, SP: Autores Associados, 2006.

PRIORI, Claudia. Retratos da violência de gênero: denúncias na Delegacia da Mulher de Maringá. Maringá:Eduem,2007.

SAFFIOTI, Heleieth I.B. (2001). Contribuições feministas para o estudo da violência de gênero. Cadernos Pagu, (16), 115-136.

SCOTT, Joan. Gênero: uma categoria útil de análise histórica. Porto Alegre: Educação e Realidade, 1995.

SILVA, L. M. A.; GOMES, E. T. A.; SANTOS, M. F. S. Diferentes olhares sobre a natureza: representação social como instrumento para educação ambiental. Estudos de Psicologia, v. 10, n. 1, p. 41-51, 2005.

WHITELAW, S. Questões de Gênero e eqüidade na formação docente. In: CARVALHO, M. E. e PEREIRA, M. Z. C. (org.). Gênero e Educação: Múltiplas faces. João Pessoa: Editora Universitária/UFPB, 2003, p. 33-44. 